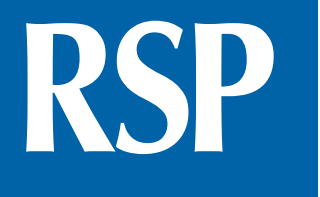

http://www.rsp.fsp.usp.br/

Revista de

Saúde Pública

\title{
Population attributable fraction: planning of diseases prevention actions in Brazil
}

\author{
Leandro Fórnias Machado de Rezende', José Eluf-Neto" \\ 1 Programa de Pós-Graduação em Medicina Preventiva. Faculdade de Medicina. Universidade de São Paulo. São \\ Paulo, SP, Brasil \\ " Departamento de Medicina Preventiva. Faculdade de Medicina. Universidade de São Paulo. São Paulo, SP, Brasil
}

\begin{abstract}
Epidemiology is the study of occurrence, distribution and determinants of health-related events, including the application of that knowledge to the prevention and control of health problems. However, epidemiological studies, in most cases, have limited their research questions to determinants of health outcomes. Research related to the application of knowledge for prevention and control of diseases have been neglected. In this comment, we present a description of how population attributable fraction estimates can provide important elements for planning of prevention and control of diseases in Brazil.
\end{abstract}

DESCRIPTORS: Attributable Risk. Primary Prevention. Measures of Association, Exposure, Risk or Outcome. Epidemiologic Studies.

\footnotetext{
Correspondence:

José Eluf-Neto

Av. Dr. Arnaldo, $4552^{\circ}$ andar

01246-903 São Paulo, SP, Brasil

E-mail: jelufnet@usp.br
}

Received: 20 Mar 2015

Approved: 20 Jul 2015

How to cite: Rezende LFM, Eluf-

Neto J. Population attributable

fraction: planning of diseases

prevention actions in Brazil. Rev

Saude Publica. 2016;50:30.

Copyright: This is an open-access article distributed under the terms of the Creative Commons Attribution License, which permits unrestricted use, distribution, and reproduction in any medium, provided that the original author and source are credited. 


\section{INTRODUCTION}

Epidemiology is the study of the occurrence and distribution of health-related events, including its determinants, and the application of that knowledge to the prevention and control of health problems ${ }^{16}$. In other words, epidemiology has two central actions: 1 ) to identify the causes of health-related events; 2) to promote, protect and restore the health of the population 6 . One of the clearest examples of this dual action of epidemiology was evident in the fight against cholera in London. In 1849, John Snow, when mapping the cases of cholera in London, identified that the incidence of the disease was related to the distribution of water, going against the Miasma theory, prevalent at the time. In a second moment, John Snow was involved directly in actions of prevention and control of cholera, including removal of the Broad Street pump ${ }^{6,20}$. Recently, this transfer of knowledge from epidemiological studies to planning policies and population disease prevention actions was named "translational epidemiology"1.

After Snow, many other examples throughout history have managed to fill the gap between knowledge and action ${ }^{5}$. However, in recent history, the second action of epidemiology has been neglected. Since the beginning of the so-called "Modern Epidemiology", epidemiologists have focused their actions, almost obsessively, in finding causal relations, using epidemiologic methods to this end. It is understandable that the field has taken such a path in the past, since little was known about the determinants of diseases in the population and, obviously, it is impossible to fight the unknown. However, even after the identification of these determinants, the same engagement with the second action related to epidemiology (application of knowledge for prevention and control of diseases) is not noticeable ${ }^{6}$.

The double action of epidemiology is present in the measures of association used in population studies. Two types of measure of association are used to estimate the effect of exposure in the occurrence of the disease (theoretical) ${ }^{19}: 1$ ) relative difference or incidence ratio of the disease between those exposed and not exposed to the factor; 2) absolute difference of the incidence of disease between those exposed and not exposed to the factor. The measures of association based on relative differences or ratios indicate the strength of association, and are predominantly present in etiological studies, whose main objective is to investigate the causes of health-related outcomes. Measures of association based on absolute differences, on the other hand, bring a perspective of population prevention strategies or impact on public health, since they inform the excess of risk to the disease associated with exposure. For a better understanding of the measures of association used in epidemiological studies, a vast and detailed literature is available in epidemiology textbooks ${ }^{7,19,22}$.

To illustrate the predominance of etiological studies in epidemiology, we performed a search on Medline on June 15, 2015, without date limits, using as descriptors measures of association based on relative ("relative differences" OR "prevalence ratio" OR "odds ratio" OR "risk ratio" OR "relative risk" OR "hazard ratio") and absolute differences ("absolute differences" OR "excess fraction" OR "etiologic fraction" OR "impact fraction" OR "attributable fraction" OR "attributable risk" OR "population attributable risk" OR "population attributable fraction").

In the world, we found 268,750 records based on relative differences, and only 4,784 on absolute differences. In Brazil, we found 4,352 records about the relative differences and only 82 about the absolute differences. It is worth mentioning that, possibly, part of the documents (articles, reports, books and other productions) that use measures of association based on absolute differences are in the grey literature. However, it is unlikely that the great predominance found in favor of the measures of association based on relative differences be much lower when the grey literature is considered.

In this context, we present this comment with a brief description of how estimates of population attributable fraction (PAF) can be calculated to provide important elements for planning of prevention and control of diseases actions in Brazil, enabling the approximation of epidemiologists to health care services and, consequently, to a translational epidemiology. 


\section{Population attributable fraction estimates}

PAF, based on absolute differences, estimates the proportion of the disease or health-related event that would be prevented in the population if the risk factor was eliminated. To this end, PAF provides a perspective of prevention of disease actions considering the risk of disease in exposed individuals and the prevalence of exposure in the population. Thus, high risk of disease in exposed individuals (measure based on relative difference or ratio) can have low population impact if the risk factors associated to it are rare, whereas low risk may impact public health when exposures are frequent. This concept refers to the famous Geoffrey Rose's phrase: "A large number of people at small risk may give rise to more cases of disease than a small number of people at high risk"18. In this sense, as well as the other measures of association based on absolute differences, PAF provides important information about the potential impact of prevention programs and interventions in public health, being extremely useful for policymakers, managers and decision makers ${ }^{19,22}$.

PAF, in general, is estimated in cohort studies, in which individuals exposed and not exposed to the risk factor are followed over time, allowing to measure outcome incidence in both groups. PAF can be estimated from the following equation ${ }^{13}$ :

$$
F A P=\frac{\left(I_{p o p}-I_{0}\right)}{I_{p o p}}
$$

In which, $I_{\text {pop }}$ is the incidence of the disease throughout the population, and $I_{\mathrm{o}}$ is the incidence of the disease in the exposed group.

However, in Brazil, cohort studies that allow the measurement of the PAF are still incipient, but there are some equations that allow to estimate it through available secondary data.

In 1953, Morton Levin showed that equation 1 is a function of the relative risk and the frequency of risk factor in the population. Therefore, PAF could also be estimated by the equation ${ }^{13}$ :

$$
F A P=\frac{P_{e}(R R-1)}{1+P_{e}(R R-1)}
$$

In which, $P_{\mathrm{e}}$ is the prevalence of the exposure in the population and $\mathrm{RR}$ is the relative risk.

Therefore, it would be possible to estimate PAF using epidemiological data on the prevalence of exposure in Brazil and the relative risk of disease to the exposure of interest. Several representative surveys of Brazilian population provide information of prevalence of risk and protective factors, allowing the stratification by the five regions, the Federation units, capitals and other cities. We can cite as examples of national surveys: Pesquisa de Orçamento Familiar $^{9}$ (Household Budget Survey), Sistema de Vigilância de Fatores de Risco e Proteção para Doenças Crônicas por Inquérito Telefônico ${ }^{15}$ (Risk and Protective Factors Surveillance System for Chronic Diseases by Telephone Interviews), Pesquisa Nacional de Saúde do Escolar $^{10}$ (Brazilian National Survey of School Health), and Pesquisa Nacional de Saúde ${ }^{23}$ (National Health Survey).

Relative risk, ideally, should be obtained from longitudinal studies with low risk of systematic errors and confounding. In addition, odds ratio estimates of case-control studies have also been used to estimate $\mathrm{PAF}^{14}$. These measures of association should be provided from studies that had the same target population for which PAF estimates would be calculated. However, often, these studies are not present in low-and middle-income countries, including Brazil. Therefore, in practice, available estimates used in systematic reviews with meta-analysis, in addition to international well-conducted cohort studies, are used. This RR portability from another target population assumes the following ${ }^{21}: 1$ ) exposure measured in the cohorts; and 2) latency of the disease are similar in the population where PAF will be estimated; 3) absence of effect modification. 
The limitation inherent to equation 2 is the need to use crude RR (unadjusted). However, in most cases, associations measured in epidemiological studies are affected by confounding, and adjustment strategies are incorporated. When adjusted RR estimates are used in equation 2, a bias occurs in the measurement of PAF. In the presence of positive confounding (crude RR > adjusted RR), PAF will be underestimated, while for negative confounding (crude $\mathrm{RR}<$ adjusted RR), it will be overestimated. The PAF bias will depend on the magnitude of the confounding (the higher the magnitude, the greater the bias), the prevalence of confounding variable (the lower prevalence, the greater the bias), and the strength of association between exposure and outcome (the lower the magnitude, the greater the bias) ${ }^{3}$.

In the presence of confounding, the use of the following equation is recommended ${ }^{17}$ :

$$
F A P=\frac{P_{c}\left(R R_{a d j}-1\right)}{\left(R R_{a d j}\right)}
$$

In which, $P_{\mathrm{c}}$ is the prevalence of exposure among the cases of the disease and $R R_{\text {adj }}$ is the relative risk adjusted by confounding variables.

Thus, to obtain $P_{c}$, it is necessary to measure the prevalence of the risk factor in population subgroups or, at least, consider the possible variation of exposure in this subgroup. A way to obtain it is to measure the prevalence ratio of exposure among the case population and the general population, reported in cohort studies. Knowing the relative difference of the prevalence of exposure among cases of the disease and the general population, this correction factor can be applied on the prevalence of exposure in the general population, to obtain the prevalence of exposure between cases of the disease. For example, the prevalence of physical inactivity among cases of colon cancer is 1.22 times that of the general population ${ }^{12}$. Thus, if the prevalence of physical inactivity in Brazil is approximately $20.0 \%$, we can estimate that the prevalence of physical inactivity among the cases of colon cancer in Brazil is $24.4 \%$.

When the exposure data and the values of relative risk are available, respectively, in a continuous way (example: gram/day) and per unit of exposure increase (dose-response RR), the following formula is used to obtain PAF:

$$
\mathrm{FAP}=\frac{\mathrm{R}-1}{\mathrm{R}}
$$

In which, $\mathrm{R}=\exp \left[\operatorname{In}\left(\mathrm{RR}_{\mathrm{dose}}\right) \times \bar{x}\right]$

$\mathrm{RR}_{\text {dose }}=$ relative risk of the disease per unit of exposure increase.

$\bar{x}=$ average of the target population's exposure.

This equation assumes a log-linear relationship between exposure and outcome².

These measures of impact in public health have been used by various organizations around the world to prioritize assistance, determine goals and start public policies. As an example, we can mention the World Health Organization, which, using the Global Burden of Disease study, provides information on the main modifiable risk factors for diseases and harms, used for the determination of targets for the reduction of non-communicable diseases by $2025^{25}$. In America, since 2009, the Pan American Health Organization, from the publication of estimates of deaths attributable to sodium consumption ${ }^{1}$, supports a Technical Advisory Group that aims to mobilize policies and interventions to reduce salt intake. In the United States, the Centers for Disease Control and Prevention (CDC) provide information of lost years of life, lost years of life adjusted by disability, and economic costs attributable to some risk factors (e.g.,smoking) ${ }^{b}$.

To illustrate the use of estimates in Brazil, we estimate the PAF of cardiovascular disease mortality associated with low intake of vegetables. According to data from the Pesquisa de Orçamento Familiar carried out in 2008, the average availability of vegetables in Brazilian 
homes was 74.2 grams per capita per day 9 . The minimum recommendation of intake of fruits and vegetables is 400 grams/day, which can be distributed in 240 grams of vegetables and 160 grams of fruits. A recent meta-analysis found inverse association between vegetables consumption and cardiovascular disease mortality (HR 0.96 to each serving of vegetables per day, equivalent to 77 grams/day ${ }^{24}$. Using equation 4, we estimate that approximately $9.6 \%$ of deaths from cardiovascular diseases would be prevented if the minimum recommendation of daily ingestion of vegetables was reached in Brazil.

For greater understanding about PAF estimates, a vast literature can be consulted to obtain more details on the different equations, limitations, strengths and perspectives of the method ${ }^{1,3,4,8,17,21}$. From this, it is possible to understand some public health measures of impact derived from PAF, such as lost years of life, years of life lived with disability, and lost years of life adjusted by disability ${ }^{21}$. It is also possible to obtain subsidies to estimate PAF confidence intervals, by calculating the variance of PAF or even by Monte Carlo simulations ${ }^{21}$.

\section{CONCLUSION}

The aim of this comment was to discuss the possibilities of use of PAF estimates by epidemiologists in Brazil and its importance for planning policies and prevention of diseases. We believe that epidemiologists have a key role in these actions, often neglected, and that, using the available secondary data, PAF estimates constitute an important means of approximation and work among epidemiologists and the health services.

\section{REFERENCES}

1. Benichou J. A review of adjusted estimators of attributable risk. Stat Methods Med Res. 2001;10(3):195-216. DOI:10.1191/096228001680195157

2. Boffetta P, Tubiana M, Hill C, Boniol M, Aurengo A, Masse R, et al. The causes of cancer in France. Ann Oncol. 2009;20(3):550-5. DOI:10.1093/annonc/mdn597

3. Darrow LA, Steenland NK. Confounding and bias in the attributable fraction. Epidemiology. 2011;22(1):53-8. DOI:10.1097/EDE.0b013e3181fce49b

4. Darrow LA. Commentary: errors in estimating adjusted attributable fractions. Epidemiology. 2014;25(6):917-8. DOI:10.1097/EDE.0000000000000177

5. Fine P, Victora CG, Rothman KJ, Moore PS, Chang Y, Curtis V, et al. John Snow's legacy: epidemiology without borders. Lancet. 2013;381(9874):1302-11. DOI:10.1016/S0140-6736(13)60771-0

6. Galea S. An argument for a consequentialist epidemiology. Am J Epidemiol. 2013;178(8):1185-91. DOI:10.1093/aje/kwt172

7. Gordis L. Epidemiology. 5th edition. Philadelphia: Elsevier Saunders; 2014.

8. Greenland S, Robins JM. Conceptual problems in the definition and interpretation of attributable fractions. Am J Epidemiol. 1988;128(6):1185-97.

9. Instituto Brasileiro de Geografia e Estatística. Pesquisa de orçamentos familiares, 2008-2009: análise do consumo alimentar pessoal no Brasil. Rio de Janeiro (RJ): IBGE; 2011.

10. Instituto Brasileiro de Geografia e Estatística. Pesquisa nacional de saúde do escolar 2012. Rio de Janeiro (RJ): Instituto Brasileiro de Geografia e Estatística; 2013.

11. Khoury MJ, Gwinn M, loannidis JP. The emergence of translational epidemiology: from scientific discovery to population health impact. Am J Epidemiol. 2010;172(5):517-24. DOI:10.1093/aje/kwq211

12. Lee IM, Shiroma EJ, Lobelo F, Puska P, Blair SN, Katzmarzyk PT. Effect of physical inactivity on major non-communicable diseases worldwide: an analysis of burden of disease and life expectancy. Lancet. 2012;380(9838):219-29. DOI:10.1016/S0140-6736(12)61031-9

13. Levin M. The occurrence of lung cancer in man. Acta Unio Int Contra Cancrum. 1953;9(3):531-41.

14. Levin ML, Bertell R. RE: "simple estimation of population attributable risk from case-control studies." Am J Epidemiol. 1978;108(1):78-9. 
15. Ministério da Saúde. Secretaria de Vigilância em Saúde. Vigitel Brasil 2013: vigilância de fatores de risco e proteção para doenças crônicas por inquérito telefônico. Brasília (DF): Ministério da Saúde; 2014.

16. Porta M. A dictionary of epidemiology. 5th ed. New York: Oxford University Press; 2008.

17. Rockhill B, Newman B, Weinberg C. Use and misuse of population attributable fractions. Am J Public Health. 1998;88(1):15-9. DOI:10.2105/AJPH.88.1.15

18. Rose G. Sick individuals and sick populations. Int J Epidemiol. 1985;14(1):32-8. DOI:10.1093/ije/14.1.32

19. Rothman, KJ, Greenland S, Lash TL. Modern epidemiology. 3rd ed. Philadelphia: Lippincott Williams \& Wilkins; 2008.

20. Snow J. On the mode of communication of cholera. 2nd ed. London: John Churchill; 1860.

21. Steenland K, Armstrong B. An overview of methods for calculating the burden of disease due to specific risk factors. Epidemiology. 2006;17(5):512-9. DOI:10.1097/01. ede.0000229155.05644.43

22. Szklo M, Nieto FJ. Epidemiology: beyond basics. 3rd ed. Burlington: Joes \& Bartlett Learning; 2014.

23. Szwarcwald CL, Malta DC, Pereira CA, Vieira MLFP, Conde WN, SOUZA Junior PRB, et al. Pesquisa Nacional de Saúde no Brasil: concepção e metodologia de aplicação. Cienc Saude Coletiva. 2014;19(2):333-42. DOI:10.1590/1413-81232014192.14072012

24. Wang X, Ouyang Y, Liu J, Zhu M, Zhao G, Bao W, et al. Fruit and vegetable consumption and mortality from all causes, cardiovascular disease, and cancer: systematic review and dose-response meta-analysis of prospective cohort studies. BMJ. 2014;349:g4490. DOI:10.1136/bmj.g4490.

25. World Health Organization. Global status report on noncommunicable diseases 2014. Geneva: World Health Organization; 2014.

Funding: Fundação de Amparo à Pesquisa do Estado de São Paulo (FAPESP - Process 2014/25614-4 - PhD scholarship for LFMR).

Authors' Contribution: Conception and planning of the study: LFMR, JEN. Drafting of the manuscript: LFMR, JEN. Critical review of the manuscript: JEN.

Acknowledgments: Catarina Machado Azeredo, for the comments and contributions during the development of the manuscript.

Conflict of Interest: The authors declare no conflict of interest. 